\title{
РОЛЬ ЛАПАРОСКОПИЧЕСКИХ ОПЕРАЦИЙ В ФОРМИРОВАНИИ СПАЕЧНОГО ПРОЦЕССА В БРЮШНОЙ ПОЛОСТИ
}

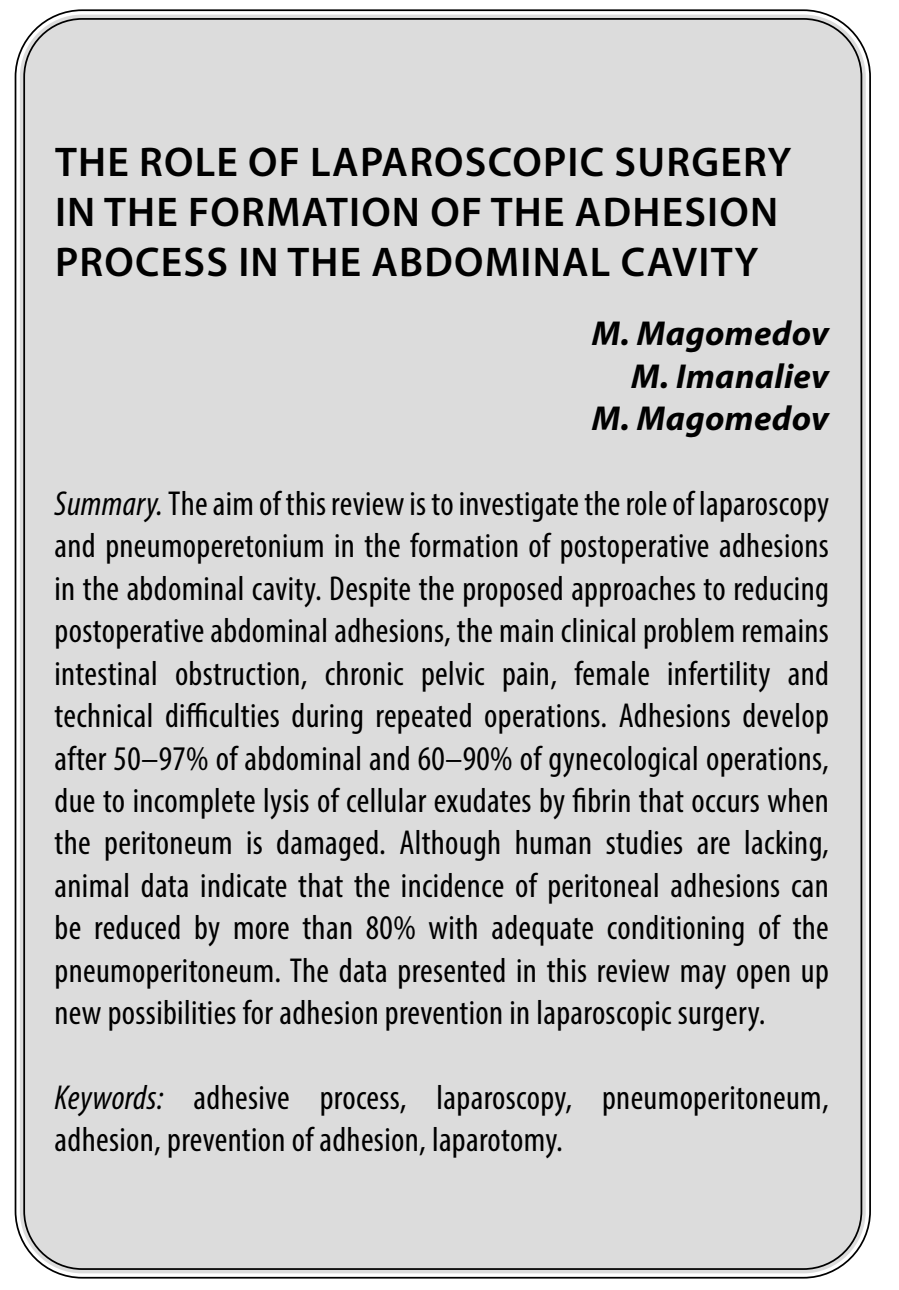

\section{Введение}

A ктуальность проблемы послеоперационных спаек в брюшной полости обусловлена их клиническим значением. В зависимости структуры и расположения перитониальных спаек, они могут, как оставаться бессимптомными, так и вызывать клинически важные осложнения, такие как кишечная непроходимость, женское бесплодие, хроническая тазовая боль и сложности во время повторной операции. Кишечная непроходимость является наиболее серьезным осложнением перитониальных спаек, поскольку может быть опасной для жизни. Спайки являются основной причиной непроходимости кишечника, на их долю приходится более $40 \%$ всех случаев кишечной непроходимости, из которых 60-70\% случаев, связаны с тонкой кишкой [1].

\author{
Магомедов Мухума Магомедович \\ Д.м.н., профессор, Дагестанский государственный \\ медицинский университет \\ muxuma@mail.ru \\ Иманалиев Магомед Расулович \\ Д.м.н., профессор, Дагестанский государственный \\ медицинский университет \\ imanaliev@mail.ru \\ Магомедов Магомед Арсеневич \\ Аспирант, Дагестанский государственный \\ медицинский университет \\ Araenovich222@mail.com
}

Аннотация. Целью это обзора является изучение роли лапароскопии и пневмоперетониума в формировании послеоперационных спаек в брюшной полости. Несмотря на предложенные подходы к уменьшению послеоперационных спаек брюшной полости основной клинической проблемой остается кишечная непроходимость, хроническая тазовая боль, женское бесплодие и технические трудности во время повторных операций. Спайки развивается после 50-97\% абдоминальных и 60-90\% гинекологических операций, вследствие неполного лизиса фибрином клеточных экссудатов, возникающих при повреждении брюшины. Хотя исследования на людях отсутствуют, данные на животных показывают, что частота возникновения перитонеальных спаек может быть уменьшена более чем на $80 \%$ при адекватном кондиционировании пневмоперитонеума. Данные приведенные в обзоре могут открыть новые возможности для профилактики адгезии в лапароскопической хирургии.

Ключевые слова: спаечный процесс, лапароскопия, пневмоперитонеум, адгезия, профилактика адгезии, лапаротомия.

Спаечная болезнь в области малого таза является одной из наиболее распространенных причин хронических тазовых болей. Сообщается, что спайки вызывают хроническую боль в области малого таза примерно у 25\% пациентов [2]. В других исследованиях было продемонстрировано, что у большого числа, пациенток с бесплодием, обусловленным спайками, боли в области таза отсутствовали [3-4]. Было высказано предположение, что боль в области малого таза является следствием ограниченной подвижности органов, вызванной спайками, а адгезиолиз приводит к облегчению симптомов [5].

\section{ᄂель $\Delta$ анного обзора}

Анализ роли лапароскопии и пневмоперетониума в формировании послеоперационных спаек в брюшной полости. 


\section{Патогенез}

перитонеальных спаек

Брюшина с поверхностью у взрослых около $10000 \mathrm{cM}^{2}$, почти равной поверхности кожи, является самым крупным органом у человека. Она служит для сведения к минимуму трения и облегчения свободного перемещения внутренних органов брюшной полости, для противодействия и локализации инфекций. Брюшина состоит из сплошного слоя мезотелиальных клеток и слоя рыхлой соединительной ткани. Мезотелиальные клетки брюшины высоко дифференцированы, и их апикальная поверхность содержит большое число длинных микроворсинок, увеличивающих функциональную поверхность поглощения и секреции. Мезотелиальные клетки секретируют гликозаминогликаны, протеогликаны и фосфолипиды, обеспечивающие скольжение, а неадгезивный гликокаликс защищает поверхность серозного покрова от инфекции. К тому же, мезотелиальные клетки могут синтезировать цитокины, хемокины, факторы роста и компоненты матрицы, которые регулируют воспаление; инициировать пролиферацию, дифференцировку и миграцию клеток; и опосредовать восстановление тканей [6]. Мезотелиальные клетки связаны друг с другом десмосомами и очень слабо прикреплены к базальной мембране.

Соединительная ткань состоит из пучков коллагеновых и эластических волокон, ориентированных в разные стороны, и богатой сети кровеносных и лимфатических сосудов $[5,7]$. Среди этих волокон и сосудов разбросаны слабо дифференцированные эпителиоидоподобные клетки, фибробласты, макрофаги, тучные и жировые клетки $[2,7,8]$.

Интактная брюшная полость содержит 3-50 мл перитонеальной жидкости с белками плазмы, включая большое количество фибриногена, и различные свободно плавающие клетки, такие как макрофаги, лимфоциты, эозинофилы, тучные клетки и дескваматированные мезотелиальные клетки [9].

Повреждение брюшины, вызванное хирургическим вмешательством или инфекцией, инициирует воспалительную реакцию, которая увеличивает концентрацию белков, образуя фибринозный экссудат и формирование фибрина $[2,10]$. Активация каскада коагуляции превращает протромбин (фактор II) в тромбин (фактор Ila) по общему пути, затем тромбин запускает превращение фибриногена в мономеры фибрина, которые взаимодействуют друг с другом и полимеризуются. Изначально растворимый полимер становится нерастворимым для некоторых факторов свертывания крови, таких как фактор XIIIa, и откладывается на раневой поверхности $[3,11]$.
Внутри этого фибринозного экссудата полиморфноядерные нейтрофилы (ПМН), макрофаги, фибробласты и мезотелиальные клетки мигрируют, пролиферируют и дифференцируются. Увеличивается количество макрофагов и изменяются их функции, они становятся наиболее важным компонентом популяции лейкоцитов после 5-го дня [7, 12]. Макрофаги более точно фагоцитируют, обладают большей активностью и выделяют различные вещества, включая цитокины и факторы роста, которые рекрутируют новые мезотелиальные клетки на раневую поверхность $[6,13]$. Мезотелиальные клетки мигрируют, образуют островки по всей поврежденной области и, размножаясь, покрывают ее. Этот процесс повторной эпителизации отличается от процесса, происходящего в коже, потому как вся поверхность эпителизируется одновременно, а не постепенно. Следовательно, данный процесс не зависит от размера повреждения и завершается через 5-7 дней $[12,14]$. Механизм мезотелиального заживления предполагает участие стволовых клеток, что согласуется с тем фактом, что мезотелиальные стволовые клетки могут дифференцироваться, и сами в свою очередь, являются стволовыми клетками $[8,15]$.

Полиморфоядерные клетки, макрофаги, фибробласты и мезотелиальные клетки выделяют различные вещества, включая компоненты системы плазминогена, метаболиты арахидоновой кислоты, активные формы кислорода, цитокины и факторы роста, которые модулируют процесс заживления в брюшной полости и формирование адгезии на разных стадиях $[14,16]$.

Хотя фибринозный экссудат и отложение фибрина являются важными составляющими восстановления нормальной ткани, ими не восстанавливается полностью предоперационное перитонеальное состояние. Деградация фибрина регулируется системой плазминогена, при этом неактивный проферментный плазминоген превращается в активный плазмин с помощью активаторов плазминогена (АП), а процесс подавляется ингибиторами активатора плазминогена [1, 17]. Плазминоген - это гликопротеин, синтезируемый в печени, который присутствует практически во всех тканях. Являясь неактивным предшественником плазмина, сериновой протеазы, плазминоген очень эффективен при деградации фибрина в продукты распада фибрина (ПРФ) и играет роль на других стадиях восстановления тканей, таких как деградация внеклеточного матрикса $[7,8,18]$, активация проферментов семейства матричных металлопротеаз (MМР) $[13,19]$ активация факторов роста.

Основным активатором плазминогена (PA) является активатор плазминогена тканевого типа (tPA), который экспрессируется в эндотелиальных клетках, мезотели- 
альных клетках и макрофагах. tРА обладает высоким сродством к фибрину и связывается со специфическим рецептором, выполняя профибринолитическую функцию. Следовательно, в присутствии фибрина скорость активации плазминогена значительно повышается [2, 7, 20]. Другим активатором плазминогена является сериновая протеаза урокиназного типа РА (uPA). Его свойства отличаются от свойств ТРА, поскольку в UPA отсутствует аффинное связывание с фибрином и, следовательно, для она ограничена в своей способности активировать плазминоген [20].

Ингибиторы активатора плазминогена 1-го и 2-го типов (ИАП-1, ИАП-2) могут противодействовать образованию неактивных комплексов. Гликопротеин ИАП-1 является наиболее мощным ингибитором ТРA и иРА и экспрессируется в эндотелиальных клетках, мезотелиальных клетках, макрофагах, тромбоцитах и фибробластах. Гликопротеин ИАП-2 является более слабым ингибитором ТРA и иРА и экспрессируется в мезотелиальных клетках, макрофагах и эпителиальных клетках. Роль других ИАП в перитонеальном фибринолизе остается неизвестной. Плазмин может быть непосредственно ингибирован ингибиторами плазмина (то есть 2-макроглобулином, a2-антиплазмином и а1-антитрипсином), но их роль в перитонеальном фибринолизе также не достаточно четко определена $[7,17,21]$.

Баланс между отложением и деградацией фибрина имеет решающее значение при определении нормального заживления брюшины или адгезии. При полном распаде фибрина происходит нормальное заживление брюшины. Напротив, распадаясь не полностью, фибрин служит каркасом для фибробластов и врастания капилляров.

\section{^апароскопическая хирургия и формирование амгезии}

Существует ряд исследований, показавших, что лапароскопия является менее адгезогенной, чем лапаротомия, но их данные не являются окончательными. Некоторые авторы сообщают о меньшем количестве спаек типа 1В после лапароскопии, чем после лапаротомии $[6,22]$. Сообщалось также о меньшем количестве спаек типа 1 А и типа 2A-B после лапароскопии у кроликов [17], что не было подтверждено в других исследованиях на кроликах [23]. У людей рандомизированное клиническое исследование сравнивающее лапаротомию и лапароскопию (т.е. пациенты, перенесшие хирургическое лечение по поводу внематочной беременности, а затем перенесшие лапароскопию повторно), продемонстрировали меньшее количество спаек типа 1 А и типа 2А-В в группе лапароскопии $[6,24]$. Другое не рандомизированное клиническое исследование также продемонстрировало меньшее образование адгезии после лапароскопии [17, 25]. В исследовании Diamond et al., 1987 сообщается о низкой частоте спаек типа 1B, очень низкой частоте спаек типа 1A, и высокая частота спаек типа 2 после лапароскопии [3].

Приведенные данные не позволяют сделать однозначного заключения, но при этом можно предположить, что лапароскопия очень редко вызывает спайки типа 1A, что лапароскопия имеет некоторые преимущества для спаек типа 1B, и что лапароскопия аналогична лапаротомии для спаек 2A-B типа.

Чтобы интерпретировать эти данные, важно подчеркнуть различия между лапароскопией и лапаротомией с точки зрения прямой травмы, вызванной самим хирургическим вмешательством, и косвенной травмы, которая может быть вызвана перитонеальной средой. Выполненная высококвалифицированными хирургами лапароскопия должна вызывать меньшую прямую хирургическую травму из-за осторожного обращения с тканями, тщательного гемостаза, постоянного орошения, использования микрохирургических инструментов и меньшего операционного поля, что может снизить риск формирования адгезии. С другой стороны, лапароскопия и лапаротомия выполняются в различных газовых средах: пневмоперитонеум $\mathrm{CO}_{2}$ для первых и воздух для вторых. Лапароскопия с применением $\mathrm{CO}_{2}$, вызывает некоторые неблагоприятные системные и местные эффекты.

\section{Системные и местные эффекты $\mathrm{CO}_{2}$ пневмоперитонеума}

Системно $\mathrm{CO}_{2}$ пневмоперитонеум ухудшает венозный возврат в зависимости от внутрибрюшного давления $[15,17,26]$ и вызывает абсорбцию $\mathrm{CO}_{2}$ из брюшной полости, что приводит к ацидозу и гиперкапнии $[15,17$, $18,27]$, которые при отсутствии адекватно компенсированой вентиляции могут отрицательно воздействовать на сердечно-сосудистую и дыхательную функции [25, 28]. Пневмоперитонеум также вызывает гипотермию [6, $17,29]$, уменьшает перфузию с возникающим оксидативным стрессом [17], что обуславливает послеоперационную боль $[15,18]$.

В местном масштабе $\mathrm{CO}_{2}$ пневмоперитонеум вызывает сухость [11, 15], перитонеальный ацидоз [11], что может способствовать подавлению функций макрофагов брюшной полости. Кроме того, $\mathrm{CO}_{2}$ изменяет микроциркуляцию в брюшной полости $[6,11]$ и перитонеальную жидкость, модулирует местную иммунную систему и воспалительную реакцию, и ингибирует перитонеальную плазминовую систему, приводя к перитонеальному гипофибринолизу. 
Также было продемонстрировано, что пневмоперитонеум является кофактором в формировании послеоперационной адгезии [15, 189]. В исследовании, оценивающем влияние профилактики на формирование адгезии у кроликов, показано, что более длительные лапароскопические операции были связаны с большим количеством спаек, а профилактика позволяла сократить продолжительность операции и снизить частоту формирования адгезии [20].

На основании этих наблюдений предполагалось, что хирургическая травма была более тяжелой во время более длительных операций, о которых сообщалось в начале исследования, и оставалась неопределенной, определяя специфический вклад каждого фактора (т.е. хирургическая травма, продолжительность операции и пневмоперитонеум) в формирование адгезии.

Для оценки влияния продолжительности операции и превмоперитониума на спаечный процесс были разработаны экспериментальные лапароскопические модели, а оперативные вмешательства выполнялись высококвалифицированными хирургами. Первой оцененной переменной была продолжительность $\mathrm{CO}_{2}$ пневмоперитонеума. Действительно, поражения были выявлены примерно через 3-5 минут от начала операции, но пневмоперитонеум поддерживался в течение разных периодов времени. Поскольку образование адгезии явно увеличивалось с продолжительностью пневмоперитонеума, было сделано предположение, что пневмоперитонеум является кофактором в формировании адгезии [24, 27]. В последствии была проведена серия экспериментов для оценки различных параметров, связанных с пневмоперитонеумом, для выявления потенциальных вовлеченных механизмов (например, перитонеальной гипоксии, перитонеального ацидоза, гиперкарбии, высыхания, гипотермии) [28, 29].

\section{Пневмоперитонеум-инАушированная} гипоксия как Авижуший механизм

Было выдвинуто предположение, что пневмоперитонеум сжимает капиллярный поток в поверхностных слоях брюшины, вызывая ишемию, что может обусловить гипоксический перитонеальный ответ, в конечном итоге приводящий к образованию адгезии. Эта гипотеза была проверена путем оценки влияния продолжительности пневмоперитонеума, давления и инсуффляции газа $[6,16]$.

В серии экспериментальных исследований с использованием $\mathrm{CO}_{2}$ и гелиевого пневмоперитонеума было продемонстрировано, что адгезия увеличивается с продолжительностью пневмоперитонеума и давле- нием инсуффляции, без различий между типом инсуффляционного газа. Кроме того, сообщалось, что адгезия уменьшалась при добавлении 2-4\% кислорода к пневмоперитонеуму, при этом при более высоких концентрациях кислорода (например, 12\%) данный эффект не наблюдался $[17,18,20]$.

Чтобы понять роль перитонеальной гипоксии, важно иметь в виду, что в нормальных условиях периферические клетки получают кислород из сосудистой сети и имеют парциальное давление кислорода $\left(\mathrm{pO}_{2}\right)$ 23 мм рт. ст. (5-40 мм рт.ст.), в зависимости от типа клеток. Это внутриклеточное парциальное давление кислорода является результатом постепенного его снижения от 160 мм рт.ст. в воздухе, до 95 мм рт.ст. в артериальном конце капилляров и до 40 мм. рт.ст. в интерстициальной жидкости. Пневмоперитонеум, в зависимости от давления и времени воздействия и, независимо от инсуффляционного газа, будет сжимать капиллярный поток в поверхностных слоях брюшины, уменьшая перфузию тканей, вызывая ишемию и снижая $\mathrm{pO}_{2}$ в мезотелиальных клетках до гипоксического уровня $[3,11$, $17,27]$.

Кроме того, инсуффляционный газ, присутствующий в брюшной полости, будет диффундировать через апикальную поверхность мезотелиальных клеток в кровоток, уменьшая мезотелиальное $\mathrm{pO}_{2}$ и вызывая гиперкапнию и ацидоз, при отсутствии вспомогательной вентиляции. Во время стандартной лапароскопии $\left(100 \% \mathrm{CO}_{2}\right)$ мезотелиальные клетки не получают достаточного количества кислорода из капилляров, и чистый $\mathrm{O}_{2}$, присутствующий в брюшной полости, диффундирует в мезотелиальные клетки. Во время лапароскопии с использованием $\mathrm{CO}_{2}$ пневмоперитонеума с 3\% кислородом, мезотелиальные клетки также не получают достаточного количества кислорода из капилляров. Но, поскольку инсуффляционный газ имеет $p=23$ мм рт. ст., что соответствует нормальному внутриклеточному давлению, клетки могут поглощать кислород, присутствующий в брюшной полости, повышая внутриклеточное давление до физиологического уровня. Во время лапароскопии с использованием $\mathrm{CO}_{2}$ пневмоперитонеума с 12\% кислорода, мезотелиальные клетки также не получают достаточное количество кислорода из капилляров, но, поскольку инсуффляционный газ имеет $\mathrm{p}=92$ мм.рт.ст., кислород диффундирует в мезотелиальные клетки, увеличивая внутриклеточное давление до уровня выше нормального $[2,13]$.

Ключевая роль перитонеальной гипоксии также подтверждается отчетом о тканевом $\mathrm{pO}_{2}$, измеренном с помощью гибкого микрокатетера, имплантированного в брюшную стенку крыс. Показано, что как $\mathrm{CO}_{2}$ так и гелиевый пневмоперитонеум уменьшают $\mathrm{pO}_{2}$ при- 
мерно до 5 мм. рт.ст., тогда как инсуффляция негипоксичной газовой смесью $\left(80 \% \mathrm{CO}_{2}\right.$ и $\left.20 \% \mathrm{O}_{2}\right)$ не вызывает значительных изменений $[6,16]$.

Хотя предполагаемая $\mathrm{CO}_{2}$ пневмоперитонеум-индуцированная перитонеальная гипоксия не была подтверждена другими авторами с использованием неповрежденной лапароскопической модели брюшной полости $[15,17]$, последующие исследования в той же группе с использованием одной и той же модели как с ранением, так и без показало, что поврежденная брюшина четко демонстрировала клеточную гипоксию во время пневмоперитонеума $\mathrm{CO}_{2}$ при высоких давлениях инсуффляции, как в поврежденных, так и в отдаленных участках брюшины [18].

\section{Пневмоперитонеум-инАушированный аци механизм}

Связь между ацидозом / гиперкапнией, вызванным пневмо-перитонеумом $\mathrm{CO}_{2}$, и образованием адгезии была рассмотрена на лапароскопической модели, в которой экспериментальные животные с эндотрахеальной интубацией механически вентилировались с различными паттернами [30]. В первой серии экспериментов подвергали воздействию чистого пневмоперитонеума $\mathrm{CO}_{2}$ во время лапароскопической операции для индукции спаек, которые оценивались на 7-й день после операции. Во второй серии экспериментов животных подвергали воздействию только анестезии или анестезии с $\mathrm{CO}_{2}$ пневмоперитонеумом, и газы артериальной крови измерялись в конце процедуры. Частота образования спаек была выше у животных с плохой вентиляцией и снижалась при более высокой скорости вентиляции (мл/мин). По сравнению с животными, которым проводилась только анестезия, пневмоперитонеум $\mathrm{CO}_{2}$ повышал $\mathrm{pCO}_{2}$ и снижал $\mathrm{pH}[3,12]$. Эти эффекты были более выражены у животных с плохой вентиляцией и их частота снижалась при соответствующей вентиляции.

Приведенные данные свидетельствуют о наличии связи между $\mathrm{CO}_{2}$ пневмоперитонеум-индуцированными ацидозом и гиперкапнией с образованием спаек. Механизм, посредством которого ацидоз и гиперкапния становятся кофактором образования адгезии, остается неясным. Углекислый газ при пневмоперитоуме вызывает респираторный ацидоз, который приводит к метаболическому ацидозу и метаболической гипоксии [7]. Это может усиливать ишемическую гипоксию в брюшине, что предположительно является движущим механизмом усиления адгезии. Очевидно, что нельзя исключать непосредственное влияние ацидоза и гиперкарбии на клетки и молекулы, участвующие в формировании адгезии. Действительно, ацидоз влияет на функции лимфоцитов и макрофагов, изменяя клеточную и гуморальную иммунную функцию [1, 3], повышает экспрессию VEGF независимо от гипоксии, которая, как сообщалось, участвует в формировании адгезии $[3,6,10]$.

Хотя такого рода исследования трудно воспроизвести на людях, и клиническая значимость данных неясна, важность ацидоза и гиперкарбии, вызванных пневмоперитонеумом $\mathrm{CO}_{2}$ следует принимать во внимание для пациентов, находящихся в положении тренделенбурга или с ограниченной сердечно-сосудистой адаптацией, таких как пациенты с ожирением и курильщики, а также для лапароскопической хирургии забрюшинного пространства или при длительных операциях [3, 8].

\section{Вызванная пневмоперитонеумом и изменения температуры и сухость в брюшной полости}

Абдоминальная инсуффляция со стандартным сухим и холодным $\mathrm{CO}_{2}$ для создания пневмоперитонеума определяет, что газ, поступающий в полость, будет нагрет до достижения равновесного значения температуры между холодным газом и теплой брюшиной и будет увлажнен для достижения и равновесия. Действительно, для достижения равновесия брюшина теряет воду и снижается ее температура, что протекает с потреблением энергии и, следовательно, вызывает гипотермию у пациента $[6,17]$. Энергия, необходимая для подогрева холодного газа $\left(0,00003\right.$ кал для нагрева 1 мл $\mathrm{CO}_{2}$ на $\left.1{ }^{\circ} \mathrm{C}\right)$ намного меньше энергии, необходимой для увлажнения сухого газа (577 кал для испарения 1 г воды) [29]. Следовательно, пневмоперитонеумом вызывается гипотермия и сухость в брюшной полости, причем оба эффекта тесно взаимосвязаны $[4,5]$.

Сухость в брюшной полости будет иметь тенденцию к продолжению до тех пор, пока пневмоперитонеум не достигнет $100 \%$ относительной влажности, количество воды удерживаемое газом, по отношению к максимальному количеству, которое может удерживаться при определенной температуре. Следовательно, этот процесс будет зависеть от времени воздействия инсуффляционного газа и от температуры инсуффляционного газа. Данный эффект имеет решающее значение, потому как абсолютная влажность газа в миллиграммах воды в литре газа выше при более высоких температурах, и поэтому 100\%-ная относительная влажность будет достигнута только при большем количестве воды, и, следовательно, тем большим будет высыхание [3, 7].

Было высказано предположение, что высыхание, вызванное сухим и холодным пневмоперитонеумом 
$\mathrm{CO}_{2}$, будет способствовать развитию спаек брюшины. Исследования in vitro подтверждают, что степень высыхания зависит от скорости потока газа через увлажненную поверхность. Когда сухой и холодный $\mathrm{CO}_{2}$ циркулирует, происходит потеря воды в зависимости от скорости потока; чем выше поток, тем большее высыхание наблюдается $[3,13]$. Учитывая, что высыхание зависит от потока, влияние сухого $\mathrm{CO}_{2}$ с различной скоростью потока в брюшной полости при формировании адгезии оценивали на экспериментальных животных [1, $4,5]$. Поскольку адгезия увеличивается с увеличением скорости потока, ключевая роль обезвоживания в патогенезе процесса была очевидна. Однако, поскольку высыхание и переохлаждение тесно связаны, конкретный вклад каждого фактора в формирование адгезии не всегда возможно определить $[15,17]$.

Во время серии экспериментов, выполненных на модели лапароскопических операций стало очевидно, что у животных с более низкой температурой тела развивается меньше спаек, чем у нормотермических. Было также подтверждено снижение адгезии при гипотермии. В соответствии с этими наблюдениями, другие данные у животных показали, что инсуффляция брюшины холодным солевым раствором снижала частоту послеоперационных спаек, тогда как ирригация теплым солевым раствором увеличивала их число. У людей локальная гипотермия после лапаротомии, как сообщалось, уменьшает воспалительную реакцию и увеличивает перистальтику кишечника, тем самым снижая адгезию $[6,17]$.

Чтобы устранить чистый эффект обезвоживания без обычной связи с гипотермией, на разработанной в эксперименте модели животные подвергались воздействию сухого и холодного $\mathrm{CO}_{2}$ пневмоперитонеума с различными скоростями потока через брюшную полость. Как и ожидалось, образование адгезии увеличивалось с высыханием. Кроме того, адгезия, вызванная обезвоживанием, была предотвращена с помощью увлажненного газа [15], что было подтверждено другими группами у экспериментальных животных [13]. Интересно, что эта вызванная обезвоживанием, адгезия была также снижена, при развитии у животных нормально ассоциированной гипотермии [15], что указывает на то, что и высушивание, и гипертермия вносят независимый вклад в формирование адгезии.

Несколько механизмов могут быть вовлечены в этот благоприятный эффект гипотермии и вредное воздействие обезвоживания. Гипотермия может уменьшить адгезию, защищая ткани и клетки от вызванной пневмоперитонеумом гипоксии, поскольку потребление кислорода клетками уменьшается с температурой. Действительно, переохлаждение снижает общую скорость метаболизма мозга во время ишемии, замедляя расще- пление глюкозы, фосфокреатина и АТФ, а также образование лактата и неорганического фосфата [17]. Кроме того, гипотермия снижает выработку АФК во время реперфузии в некоторых тканях и органах [15], улучшает восстановление энергетических параметров во время реперфузии. Данная гипотеза об обезвоживании, как движущем механизме формирования адгезии подтверждается данными, демонстрирующими, что сухой и холодный $\mathrm{CO}_{2}$ изменяет морфологию мезотелия (то есть разрушает гексагональную структуру, уменьшает микроворсинки и вызывает гибель клеток), что может способствовать развитию послеоперационных спаек $[15,187]$.

\section{Зак^ючение}

В настоящее время вопрос о том, какие изменения, вызванные пневмоперитонеумом, способствуют адгезии из-за чисто локальных эффектов или из-за более общих и системных эффектов до сих пор не разрешен. Появляются данные, свидетельствующие о том, что патогенез образования адгезии не ограничивается операционным участком, а может быть задействована вся брюшная полость и, возможно, весь организм. В соответствии с этой гипотезой недавно на экспериментальных животных было продемонстрировано, что адгезия увеличивается в месте поражения при манипуляциях с удалением сальника или резекцией кишки и данный эффект зависит от тяжести вмешательства [1, 3].

Хотя большинство данных получены из экспериментальных исследований, значимость перитонеальной среды в патогенезе адгезии очевидна. Пневмоперитонеум-индуцированная перитонеальная гипоксия может быть снижена путем добавления 3\% кислорода к $\mathrm{CO}_{2}$ пневмоперитонеуму, тогда как его прямые последствия, такие как активация PAl-1, VEGF, могут быть предотвращены с помощью специфических антител против этих факторов. Некоторые предварительные данные исследований на людях указывают на то, что добавление кислорода также может иметь некоторые полезные эффекты с точки зрения уменьшения послеоперационной боли.

Индуцированная пневмоперитонеумом ишемия-реперфузия генерирует АФК, что может быть минимизировано путем снижения давления инсуффляции [3] или путем ишемического прекондиционирования, концепции, которая состоит из коротких периодов инфляции и дефляция при образовании пневмоперитонеума $[27,28]$.

Вызванное пневмоперитонеумом обезвоживание брюшины может быть уменьшено путем увлажнения инсуффляционного газа, что, помимо снижения адгезии, будет иметь другие местные и системные полез- 
ные эффекты, такие как меньшее разрушение мезотелия, меньшее послеоперационный болевой синдром и меньшее количество переохлаждений.

Действительно, некоторые исследования на животных показывают меньшее повреждение брюшины при использовании теплого и увлажненного $\mathrm{CO}_{2}[17,26]$. Этот защитный эффект, однако, не является окончательным, потому что другие исследования не смогли прийти к тем же выводам $[16,18,20]$.

Утверждается, что сухой и холодный газ, используемый для создания пневмоперитонеума, способствует возникновению послеоперационной боли, поскольку основной источник боли и дискомфорта после лапароскопии исходит из брюшины, а не из кожи или брюшной стенки [18]. Несколько исследований, проведенных на людях, показали, что использование теплого и увлажненного инсуффляционного газа связано с меньшими послеоперационными болями и потребностями в анальгезии [6]. Кроме того, в других исследованиях сообщалось, что применение теплого и увлажненного газа было связано с более быстрым возвращением пациента к нормальной деятельности и сокращением сроков пребывания в стационаре $[17,18]$.
Научные исследования продемонстрировали, что поддержание брюшной полости слегка охлажденной (то есть, $32{ }^{\circ} \mathrm{C}$ ) и увлажненной, а не теплой и увлажненной, может быть эффективно в предотвращении адгезии, поскольку локальная гипотермия способствует минимизации локального воспаления и снижению токсических эффектов гипоксии и процессов ишемии-реперфузии $[15,17]$.

Научные исследования на модели экспериментальных животных демонстрируют, что правильная хирургическая техника, позволяющая избежать, как можно большего числа побочных манипуляций и повреждений, снижает адгезию примерно на 50\%, а кондиционирование $\mathrm{CO}_{2}$ пневмоперитонеума с увлажнением и добавлением 3-4\% кислорода, имеет дополнительный профилактический эффект $[17,18]$.

Актуальность данных стратегий с целью снижения и предотвращения адгезии в конкретных перитонеальных условиях должна быть подтверждена у более крупных животных и у людей [27], что позволит направить усилия на кондиционирование брюшной полости в стратегии снижения послеоперационной боли и предотвращения адгезии $[6,29]$.

\section{ЛИТЕРАТУРА}

1. Binda M.M., Koninckx P.R. Prevention of adhesion formation in a laparoscopic mouse model should combine local treatment with peritoneal cavity conditioning. Hum Reprod. 2009;24(6):1473-9. doi: 10.1093/humrep/dep053.

2. Binda M.M., Molinas C.R., Bastidas A., Koninckx P.R. Effect of reactive oxygen species scavengers, antiinflammatory drugs, and calcium-channel blockers on carbon dioxide pneumoperitoneum-enhanced adhesions in a laparoscopic mouse model. Surg Endosc. 2007;21(10):1826-34. doi: 10.1007/s00464-007-9296-7.

3. Binda M.M., Molinas C.R., Bastidas A., Koninckx P.R. Efficacy of barriers and hypoxia-inducible factor inhibitors to prevent $C 02$ pneumoperitoneum-enhanced adhesions in a laparoscopic mouse model. Journal of Minimally Invasive Gynecology. 2007a;14:591-599. doi:10.1016/j.jmig.2007.04.002

4. Binda M.M., Molinas C.R., Hansen P., Koninckx P.R. Effect of desiccation and temperature during laparoscopy on adhesion formation in mice. Fertil Steril. 2006 Jul;86(1):166-75. doi: 10.1016/j.fertnstert.2005.11.079

5. Erecinska M., Thoresen M., Silver I.A. Effects of hypothermia on energy metabolism in Mammalian central nervous system. J Cereb Blood Flow Metab. 2003;23(5):513-30. doi: 10.1097/01.WCB.0000066287.21705.21.

6. Ahmad G., 0'Flynn H., Hindocha A., Watson A. Barrier agents for adhesion prevention after gynaecological surgery. Cochrane Database Syst Rev. 2015;4: CD000475.

7. Bessell J.R., Ludbrook G., Millard S.H., Baxter P.S., Ubhi S.S., Maddern G.J. Humidified gas prevents hypothermia induced by laparoscopic insufflation: a randomized controlled study in a pig model. Surg Endosc. 1999;13(2):101-5. doi: 10.1007/s004649900914.

8. Binda M.M., Hellebrekers B.W., Declerck P.J., Koninckx P.R. Effect of Reteplase and PAI-1 antibodies on postoperative adhesion formation in a laparoscopic mouse model. Surg Endosc. 2009;23(5):1018-25. doi: 10.1007/s00464-008-0111-x.

9. Binda M.M., Molinas C.R., Koninckx P.R. Reactive oxygen species and adhesion formation: clinical implications in adhesion prevention. Hum Reprod. 2003;18(12):2503-7. doi: 10.1093/humrep/deg481.

10. Bruckner B.A., Blau L.N., Rodriguez L. Microporous polysaccharide hemosphere absorbable hemostat use in cardiothoracic surgical procedures. Journal of Cardiothoracic Surgery; 2014. p. 9.

11. Demco L. Effect of heating and humidifying gas on patients undergoing awake laparoscopy. J Am Assoc Gynecol Laparosc. 2001;8(2):247-51. doi: 10.1016/ s1074-3804(05)60585-3.

12. Elkelani 0.A., Molinas C.R., Mynbaev 0., Koninckx PR. Prevention of adhesions with crystalloids during laparoscopic surgery in mice. J Am Assoc Gynecol Laparosc. 2002;9(4):447-52. doi: 10.1016/s1074-3804(05)60517-8.

13. Hazebroek E.J., Schreve M.A., Visser P., De Bruin R.W., Marquet R.L. and Bonjer H.J. Impact of temperature and humidity of carbon dioxide pneumoperitoneum on body temperature and peritoneal morphology. J LaparoendoscAdv Surg Tech A. 2002;12:355-364. 
14. Hoffmann N.E., Siddiqui S.A., Agarwal S., McKellar S.H., Kurtz H.J., Gettman M.X., Ereth M.H. Choice of hemostatic agent influences adhesion formation in a rat cecal adhesion model. / Surg Res 2009;155(1):77-81.

15. Hoffmann N.E., Siddiqui SA, Agarwal S. et al. Choice of hemostatic agent influences adhesion formation in a rat cecal adhesion model. J Surg Res. 2009;155:77-81.

16. Hong G., Vilz T.0., Kalff J.C., Wehner S. Peritoneal adhesion formation. Der Chirurg: Zeitschriffur alle Gebiete der operativen Medizen. 2015;86(2): 175-180.

17. Horiguchi T., Shimizu K., Ogino M., Suga S., Imamasu J. and Kawase T. Postischemic-Hypothermia inhibits the generation of hydroxyl radical following transient forebrain ischemia in rats. J Neurotrauma. 2003;20:511-520.

18. Koninckx P.R., Binda M.M., Corona R., Molinas C.R. Postoperative adhesions and their prevention. In: Reconstructive and Reproductive Surgery in Gynecology, Gomel V, Brill Al (eds). Informa Healthcare: London, 2010; 8-17.

19. Lalountas M., Ballas K.D., Michalakis A., Psarras K., Asteriou C., Giakoustidis D.E., Nikolaidou C., Venizelos I., Pavlidis T.E., Sakantamis A.K. Postoperative adhesion prevention using a statin-containing cellulose film in an experimental model. Br / Surg 2012;99(3): 423-429.

20. Lauder C.I., Garcea G., Strickland A., Maddern G.J. Use of a modified chitosan-dextran gel to prevent peritoneal adhesions in a rat model. J Surg Res. 2011;171(2): 877-882.

21. Lauder C.I., Garcea G., Strickland A., Maddern G.J. Use of a modified chitosan-dextran gel to prevent peritoneal adhesions in a rat model. J Surg Res. 2011;171:877-882.

22. Poehnert D., Abbas M., Kreipe H.H., Klempnauer J., Winny M. High repro-ducibility of adhesion formation in rat with meso-stitch approximation of injured cecum and abdominal wall. Int JMed Sci 2015;12(1): 1-6.

23. Poehnert D., Abbas M., Kreipe H.-H., Klempnauer J., Winny M. High reproducibility of adhesion formation in rat with meso-stitch approximation of injured cecum and abdominal wall. Int J Med Sci. 2015;12:1-6.

24. Poehnert D., Abbas M., Kreipe H-H., Klempnauer J., Winny M. Evaluation of 4DryField ${ }^{\circledR}$ PH as Adhesion Prevention Barrier Tested in an Optimized Adhe-sion Model (OPAM) in Rats. European Surgical Research 2015;55(4): 341-351.

25. Poehnert D., Abbas M., Kreipe H-H., Klempnauer J., Winny M. Evaluation of 4DryField ${ }^{\oplus} \mathrm{PH}$ as Adhesion Prevention Barrier Tested in an Optimized Adhesion Model (OPAM) in Rats. Eur Surg Res. 2015;55:341-51.

26. Poehnert D., Grethe L., Maegel L. et al. Evaluation of the Effectiveness of Peritoneal Adhesion Prevention Devices in a Rat Model. Int J Med Sci. 2016;13:524-532.

27. Pouly J.L., Seak-San S. Adhesions: Laparoscopy versus laparotomy. Surgery on the peritoneum. Springer, New York, 2000; 183-192.

28. Singh P., Vasques D., Deleon F. Microporous Polysaccharide Hemospheres for Adhesion Prevention: A Randomized Controlled Trial. Journal of Gynecologic Surgery. 2013;29:196-202.

29. ten Broek R.P.G., Stommel M.W.J., Strik C., van Laarhoven C.JHM., Keus F., van Goor H. Benefits and harms of adhesion barriers for abdominal surgery: a systematic review and meta-analysis. The Lancet 2014;383(9911): 48-59.

(c) Магомедов Мухума Магомедович ( muxuma@mail.ru ),

Иманалиев Магомед Расулович ( imanaliev@mail.ru ), Магомедов Магомед Арсеневич ( Araenovich222@mail.com ).

Журнал «Современная наука: актуальные проблемы теории и практики» 